\title{
Understanding the staff behaviours that promote quality for older people living in long term care facilities: A realist review
}

Citation for published version (APA):

Haunch, K., Thompson, C., Arthur, A., Edwards, P., Goodman, C., Hanratty, B., Meyer, J., Charlwood, A., Valizade, D., Backhaus, R., Verbeek, H., Hamers, J., \& Spilsbury, K. (2021). Understanding the staff behaviours that promote quality for older people living in long term care facilities: A realist review. International Journal of Nursing Studies, 117, [103905]. https://doi.org/10.1016/j.ijnurstu.2021.103905

Document status and date:

Published: 01/05/2021

DOI:

10.1016/j.jinurstu.2021.103905

Document Version:

Publisher's PDF, also known as Version of record

\section{Document license:}

Taverne

Please check the document version of this publication:

- A submitted manuscript is the version of the article upon submission and before peer-review. There can be important differences between the submitted version and the official published version of record.

People interested in the research are advised to contact the author for the final version of the publication, or visit the DOI to the publisher's website.

- The final author version and the galley proof are versions of the publication after peer review.

- The final published version features the final layout of the paper including the volume, issue and page numbers.

Link to publication

\footnotetext{
General rights rights.

- You may freely distribute the URL identifying the publication in the public portal. please follow below link for the End User Agreement:

www.umlib.nl/taverne-license

Take down policy

If you believe that this document breaches copyright please contact us at:

repository@maastrichtuniversity.nl

providing details and we will investigate your claim.
}

Copyright and moral rights for the publications made accessible in the public portal are retained by the authors and/or other copyright owners and it is a condition of accessing publications that users recognise and abide by the legal requirements associated with these

- Users may download and print one copy of any publication from the public portal for the purpose of private study or research.

- You may not further distribute the material or use it for any profit-making activity or commercial gain

If the publication is distributed under the terms of Article $25 \mathrm{fa}$ of the Dutch Copyright Act, indicated by the "Taverne" license above, 


\title{
Understanding the staff behaviours that promote quality for older people living in long term care facilities: A realist review ${ }^{\text {th }}$
}

\author{
Kirsty Haunch ${ }^{\mathrm{a}}$, Carl Thompson ${ }^{\mathrm{a}, \mathrm{b}}$, Antony Arthur ${ }^{\mathrm{c}}$, Paul Edwards ${ }^{\mathrm{d}}$, Claire Goodman ${ }^{\mathrm{e}, \mathrm{f}}$, \\ Barbara Hanratty ${ }^{g, h}$, Julienne Meyer ${ }^{i}$, Andy Charlwood ${ }^{a}$, Danat Valizade ${ }^{a}$, \\ Ramona Backhaus ${ }^{j}$, Hilde Verbeek ${ }^{j}$, Jan Hamers ${ }^{j}$, Karen Spilsbury ${ }^{\mathrm{a}, \mathrm{b}, *}$ \\ a School of Healthcare, Faculty of Medicine and Health, Baines Wing (Room 2,28), University of Leeds, Leeds LS2 9JT, United Kingdom \\ ${ }^{\mathrm{b}}$ NIHR ARC Yorkshire and Humber \\ ' School of Health Sciences, University of East Anglia, Norwich, United Kingdom \\ ${ }^{\mathrm{d}}$ Dementia UK, London, United Kingdom \\ ${ }^{\mathrm{e}}$ Centre for Research in Primary and Community Care, University of Hertfordshire, Hatfield, Hertfordshire, United Kingdom \\ ${ }^{\mathrm{f}}$ NIHR ARC East of England \\ g Population Health Sciences Institute, University of Newcastle, United Kingdom

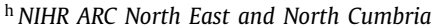 \\ i School of Health Sciences, City, University of London, United Kingdom \\ ${ }^{j}$ Department of Health Services Research, CAPHRI Care and Public Health Research Institute, Maastricht University, Maastricht, the Netherlands
}

\section{A R T I C L E I N F O}

\section{Article history:}

Received 23 September 2020

Received in revised form 11 February 2021

Accepted 13 February 2021

\section{Keywords:}

Long term care facilities

Nursing homes

Care homes

Quality

Staff behaviours

Leadership

Relationships

Realist review

\begin{abstract}
A B S T R A C T
Background: Little is known about how the workforce influences quality in long term care facilities for older people. Staff numbers are important but do not fully explain this relationship.

Objectives: To develop theoretical explanations for the relationship between long-term care facility staffing and quality of care as experienced by residents.

Design: A realist evidence synthesis to understand staff behaviours that promote quality of care for older people living in long-term care facilities.

Setting: Long-term residential care facilities

Participants: Long-term care facility staff, residents, and relatives

Methods: The realist review, (i) was co-developed with stakeholders to determine initial programme theories, (ii) systematically searched the evidence to test and develop theoretical propositions, and (iii) validated and refined emergent theory with stakeholder groups.

Results: 66 research papers were included in the review. Three key findings explain the relationship between staffing and quality: (i) quality is influenced by staff behaviours; (ii) behaviours are contingent on relationships nurtured by long-term care facility environment and culture; and (iii) leadership has an important influence on how organisational resources (sufficient staff effectively deployed, with the knowledge, expertise and skills required to meet residents' needs) are used to generate and sustain qualitypromoting relationships. Six theoretical propositions explain these findings.

Conclusion: Leaders (at all levels) through their role-modelling behaviours can use organisational resources to endorse and encourage relationships (at all levels) between staff, residents, co-workers and family (relationship centred care) that constitute learning opportunities for staff, and encourage quality as experienced by residents and families.
\end{abstract}

Crown Copyright @ 2021 Published by Elsevier Ltd. All rights reserved.

\section{What is already known about the topic?}

- Quality is complex, contested and dynamic and can refer to both quality of life and quality of care.

\footnotetext{
This review is registered with the Research Registry (unique identification number 1062).

* Corresponding author.

E-mail address: k.spilsbury@leeds.ac.uk (K. Spilsbury).
}

- Whilst 'staffing influences quality' is well established, little is known about the relationship between the long-term care workforce and quality.

- 'More' staff does not necessarily equate to better 'quality': staff numbers do not fully explain this relationship. 


\section{What this paper adds}

- A realist theory-based explanation of how staff behaviours promote quality of care as experienced by older people in longterm care facilities.

- Staff behaviours are contingent on reciprocal relationships with residents, family, and their colleagues.

- Leadership influences how organisational resources are used to promote the environments and cultures needed for qualitypromoting relationships to flourish.

\section{Introduction}

Long-term care facilities (care homes, nursing homes, residential homes) are an important, part of care for older people in many countries (Age UK 2018). The quality of these facilities varies (Spilsbury et al., 2011; Backhaus et al., 2014; Backhaus et al., 2018). Conceptually, quality is complex, often contested, and dynamic, has overlapping physical, social, psychological and emotional dimensions and can refer to both quality of life and quality of care (Spilsbury et al., 2011). Quality of care contributes to an individual's quality of life, but is not the sole determinant (Spilsbury et al., 2011).

Staff in long term care may be poorly paid, undervalued (Trinkoff et al., 2017; Han et al., 2014), and work long hours. These same staff are a key influence on quality (Rittel and Webber, 1973) and the largest operating cost for most facilities (Laing, 2008). Balancing costs whilst proving quality care is a societal priority (Kusmaul and Bunting, 2017; Skills for Care 2018). Assuming 'more staff equates to better quality' is intuitively appealing. Research suggests a more nuanced, non-linear, relationship (Backhaus et al., 2014; Backhaus et al., 2018).

Syntheses of quantitative research into relationships between staffing (numbers, mix of grades, use of temporary staff) and quality (using indicators such as incidence of falls, pressure ulcers and medication errors) suggest more long-term care facility staff (at any level) are associated with better outcomes and quality only on some measures (Spilsbury et al., 2011; Backhaus et al., 2014; Backhaus et al., 2018). Explanations are broad ranging and often atheoretical (Backhaus et al., 2014). In this review we use theory to explain the relationship between staffing and quality, going beyond the numbers and mix of staff deployed (Spilsbury et al., 2011; Backhaus et al., 2014; Backhaus et al., 2018), to examine modifiable staffing factors and their influence on an explicit version of quality. We recognise that quality is subjective and contested but can be operationalised and measured (Donabedian, 2005). Accordingly, we have started from Donabedian's (13) axiom (and our stakeholder's consensus view) that staff primarily influence quality according to, "how they make residents feel".

\section{Aims and objectives}

To achieve our primary aim of developing theory explaining the relationship between long-term care facility staffing and quality by understanding the mechanisms by which staffing promotes or hinders quality, we had three objectives:

(1) identify how staffing is reported and theorised in relation to quality for long-term care facility residents;

(2) develop evidence and theory-based explanations of how long-term care facility staffing promotes resident quality of care and quality of life, why and in what circumstances; and

(3) evaluate the strengths and limitations of the evidence-base, highlighting future research needs.

\subsection{Methods}

We undertook a realist review (see Box 1 for our working definitions of key elements) to understand why interventions (staffing) works, for whom and in what circumstances (Pawson et al., 2005; Wong et al., 2016) in the complex social interventions and systems (Pawson et al., 2005) of long-term care facilities (Anderson et al., 2003). RAMESES reporting standards guided our review processes (Wong et al., 2016).

Theory was developed in three stages using research literature and in consultation with stakeholders: (i) elicitation, (ii) development and testing, and (iii) refinement. Theory derived from research was reviewed with long-term care facility residents, relatives, staff, providers, commissioners, regulators and policy makers to sense check and improve explanation and analysis (Davidoff et al., 2015; Pawson and Tilley, 1997). See Fig. 1 for review process and document flow.

\subsection{Stage 1: theory elicitation}

\subsubsection{Defining the scope of the review: concept mining and initial} theory development

This stage provided the structure and framework for exploring and synthesising diverse research findings (Pawson et al., 2004). First, the most recent systematic review of the relationship between staffing and quality (Backhaus and V.H., 2014) was used to develop preliminary explanation by identifying key concepts and theories. Six 'If-Then' statements (Pearson et al., 2015) derived from the review's included studies (4), were further mined to develop ideas and assumptions about how and why staffing influences quality (see Supplementary material: Appendix 1). We used these statements to articulate programme theories containing possible social rules, values, or sets of interrelationships (Pawson and Tilley, 1997) that might limit or trigger programme mechanisms and their linked outcomes.

In line with Pawson et al. (2004), our programme theories were iteratively scrutinised and agreed with stakeholders to refine review scope. We had two stakeholder groups. The first was comprised of long-term care residents and relatives $(n=5)$. The second group was comprised of long-term care facility managers $(n=7)$. Our stakeholder groups each met three times during the review period (each meeting lasting 90-120 min). In the first meeting, residents and relatives directed us toward one area: the everyday human interactions that occur between staff and residents has a major influence on quality, or as our stakeholders expressed this, 'how staff made residents feel'. This focus was checked with the long-term care facility managers who agreed this an important focus. Staff behaviours were therefore identified as a key concept (or theory area) linked to quality of care experience.

We tested this by mapping staff behaviours against researchreported staffing model characteristics and quality outcomes (Madden et al., 2017; Bishop et al., 2008; Ericson-Lidman et al., 2014). This confirmed the working hypothesis. By way of illustration, in one qualitative study, behaviours such as 'getting to know the resident' and 'treating residents like their mum or dad', generated resident 'joy' and 'satisfaction' (Eldh et al., 2016). These behaviours became the focus for our review and theory development.

\subsubsection{Identifying and organising key behaviours - COM-B}

To frame our review and help isolate key behaviours and associated triggers, we used Michie et al.'s COM-B theory (Michie et al., 2011). COM-B suggests behaviour results from three interacting components in people or teams:

(1) Capabilities - the psychological or physical abilities of people to enact behaviours. The individual's psychological and phys- 


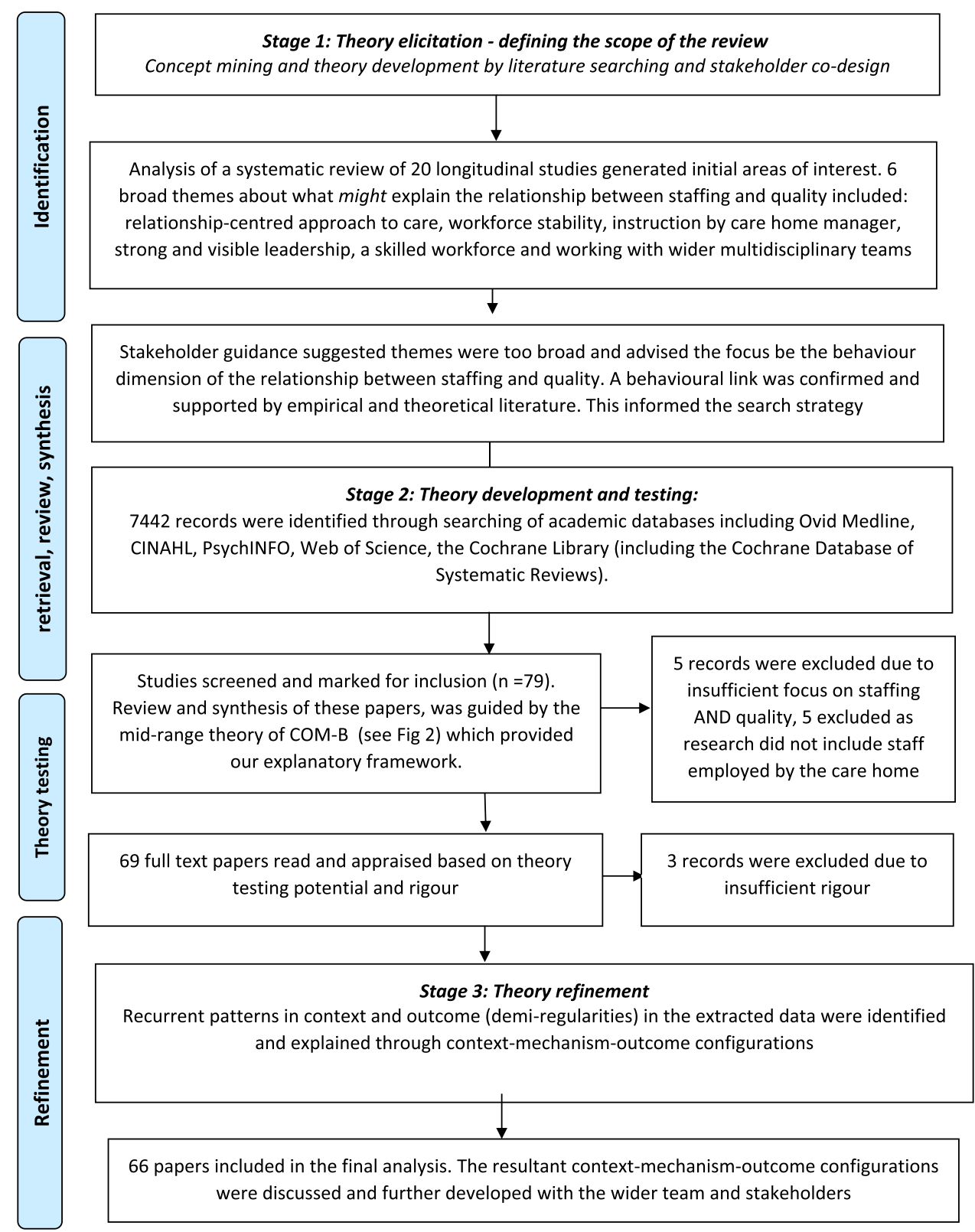

Fig. 1. Review process and document flow.

ical capacity to engage in the activity concerned. It includes having the necessary knowledge and skills.

(2) Opportunities - the physical or social environment that enables behaviours. Opportunity is defined as all the factors that lie outside the individual that make the behaviour possible or prompt it

(3) Motivations - reflective and automatic mechanisms that activate or inhibit behaviour. Motivation is defined as all those brain processes that energize and direct behaviour, not just goals and conscious decision-making. It includes habitual processes, emotional responding, as well as analytical decision-making.

Fig. 2 illustrates that opportunity and capability influence motivation; and the enacted behaviours that alter capability, motivation, and opportunity. For example, opportunities for care workers to do care differently may result in more pleasurable care deliv-

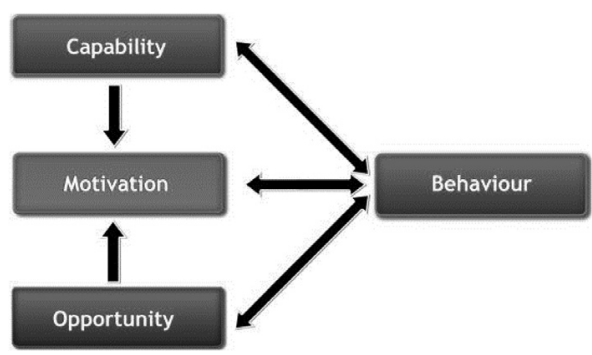

Fig. 2. The COM-B model - a framework for understanding behaviour (Michie et al., 2011).

ery/work behaviours (capability), meaning motivation is likely increased and positive behaviours repeated.

Using COM-B (Michie et al., 2011) and bespoke data extraction forms we coded data from studies on staffing and quality 
as capabilities, opportunities, motivations or behaviours. Demiregularities, or patterns, then provided the basis for contextmechanism-outcome configuration development (Pawson et al., 2005). By the end of stage 1 , our review questions had evolved to become:

- What staff behaviours influence long-term care facility residents' experience of quality?

- What influences the behaviour of long-term care facility staff?

- What impact does the interaction between staff behaviours and context have on long-term care facility residents' experience of quality?

We sense checked our review questions in our second stakeholder meetings. Stakeholders from both groups highlighted the importance of the multi-layered relationships staff had with those they care for and work with and how these relationships influence staff behaviours and quality as experienced by residents.

\subsection{Stage 2: theory development and testing}

\subsubsection{Search, appraisal, extraction and synthesis of evidence}

This stage involved systematically searching, appraising, extracting and narratively synthesising evidence to test and develop emergent programme theory from Stage 1 (Pawson et al., 2004).

\subsection{Search}

With an information scientist, we designed an inclusive search strategy to maximise data for extraction (Ford et al., 2016) around three central concepts: long-term care facilities, staffing and quality (see Supplementary materials: Appendix 2 for subject headings, terms and synonyms). We searched Ovid Medline, PsychINFO, Cinahl, Web of Science, Cochrane Database of Systematic Reviews, Cochrane Central Register of Controlled Trials online databases from inception to November 2019 with search alerts scanned to April 2020. We asked experts from our wider multidisciplinary research network (Spilsbury et al., 2017) and forward citation matched and scanned included papers' reference lists for relevant publications.

\subsection{Selection and appraisal of documents}

Search results were saved, managed and duplicates removed using EndNote. Titles and abstracts of the retrieved papers were screened for inclusion by the study team (KH, KS, CT, BH, AA, DV).

Studies were included if they:

- addressed the relationship between staffing models and quality (quality of life and/or quality of care)

- took place in a long-term care facility context

- explicitly focused on quality or, implicitly, accounts of quality similar to our working model of quality based on, "how staff make people feel'.

- addressed capabilities, opportunities, motivations and/or behaviours

Studies were excluded if they:

- did not focus on staffing AND quality

- were not research, i.e. unsystematic approach to enquiry

- were not conducted in long-term care facilities

- if they focused on healthcare professions employed by organisations other than the long term care facility - this work has already been done (Goodman et al., 2016).

Study quality was assessed qualitatively according to:

- relevance - degree of contribution to theory building and/or testing; and
- rigor - whether the method used to generate the data was credible and trustworthy (Wong et al., 2016).

Studies were included if they rigorously contributed to the initial programme theory of Stage 1. Full text papers marked for inclusion were retrieved and read in full by KH and KS. Any disagreements were resolved through discussion with members of the wider research team (CT, BH, AA, DV) and with reference to the review framework and emergent programme theory (Pawson et al., 2004).

\subsection{Data extraction}

Data on staff behaviours, behaviour triggers (capability, opportunity, motivation), and how they interacted in the long-term care setting were extracted. The data extraction table (see Supplementary materials: Appendix 3) was piloted by the wider research team (KH, KS, CT, BH, AA, DV) prior to use. $\mathrm{KH}$ and $\mathrm{KS}$ double extracted data from over a third of the included papers $(n=25$; $38 \%$ ). This was done in 3 stages: $\mathrm{KH}$ and $\mathrm{KS}$ both extracting from 5 papers then discussing, followed by two further rounds (with 10 papers in each round) with discussion. Piloting and double extraction from a sample of papers were used to promote consistent and comprehensive data extraction. $\mathrm{KH}$ extracted data for all included papers. Data from author explanations and discussions can help make explicit in what context, which mechanisms lead to which outcomes (Wong et al., 2011) and so were included.

\subsection{Stage 3: Theory refinement}

In this final stage, we refined context-mechanism-outcome configurations and examined supporting evidence in three 6090 min researcher-led discussions during Nov-December 2019 with our stakeholder groups which included: residents and relatives (group 1) and managers (group 2) of long-term care facilities, and our Study Steering Committee (SSC) members (including representatives from provider organisations, policy makers, regulators, methodologists, and members of the public). Stakeholders were invited to discuss and critically comment on the resonance, relevance, and gaps in our theories. Revision of context-mechanism-outcome configurations after each discussion led to the final set of refined context-mechanism-outcome configurations.

\section{Results}

Sixty-six studies were included: interview and/or focus groups $(n=25)$, cross-sectional design $(n=15)$, literature reviews containing new/additional studies $(n=7)$, case studies $(n=7)$, ethnographies $(n=5)$, non-ethnographic interview and observational studies $(n=2)$, mixed methods $(n=2)$, an action research study $(n=1)$, a randomised controlled trial $(n=1)$ and a pre-post intervention study $(n=1)$. Most studies were from North America ( $n=31)$ or UK/Europe $(n=24)$, followed by Australia/New Zealand $(n=9)$, Lebanon $(n=1)$ and China $(n=1)$.

Our six context-mechanism-outcome configurations are reported below and summarised in Table 1.

\subsection{Context-mechanism-outcome configuration 1: philosophies of care that promote staff-resident relationships}

A clear, managerially endorsed, philosophy putting residents at the centre (context), enables work to be structured so that a core number of consistent staff have regular and ongoing contact with a group of residents and relatives, providing opportunities to spend time understanding and responding to their preferences 
Table 1

Summary of context-mechanism-outcome configurations.

\begin{tabular}{|c|c|c|c|c|c|c|c|}
\hline \multirow[b]{2}{*}{ Theory } & \multirow[b]{2}{*}{ Context } & \multirow[b]{2}{*}{+} & \multicolumn{2}{|l|}{ Mechanism } & \multirow[b]{2}{*}{$=$} & \multirow[b]{2}{*}{ Outcome } & \multirow[b]{2}{*}{ Evidence summary } \\
\hline & & & Resource & Response & & & \\
\hline $\begin{array}{l}\text { Theory 1: } \\
\text { Resident } \\
\text { centred care }\end{array}$ & $\begin{array}{l}\text { A clear, } \\
\text { managerially } \\
\text { endorsed, } \\
\text { philosophy putting } \\
\text { residents at the } \\
\text { centre of care }\end{array}$ & + & $\begin{array}{l}\text { enables work to be structured } \\
\text { so that a core number of } \\
\text { consistent staff have regular } \\
\text { and ongoing contact with a } \\
\text { group of residents and } \\
\text { relatives, providing } \\
\text { opportunities to spend time } \\
\text { understanding and responding } \\
\text { to resident's preferences and } \\
\text { values }\end{array}$ & $\begin{array}{l}\text { to promote meaningful } \\
\text { reciprocal relationships } \\
\text { between staff and } \\
\text { residents }\end{array}$ & $=$ & $\begin{array}{l}\text { which leads, to } \\
\text { development of empathy } \\
\text { amongst staff and more } \\
\text { individual needs and } \\
\text { preferences of residents } \\
\text { being met }\end{array}$ & $\begin{array}{l}43 \text { studies contributed to } \\
\text { context-mechanism-outcome } \\
\text { configuration 1: interview } \\
\text { and/or focus groups }(n=20), \\
\text { cross-sectional }(n=7) \text {, case } \\
\text { study }(n=6) \text {, literature review } \\
(n=5) \text { ethnography }(n=4), \\
\text { and non-ethnographic interview } \\
\text { and observations }(n=1) \text {. }\end{array}$ \\
\hline $\begin{array}{l}\text { Theory 2: } \\
\text { Family as } \\
\text { experts }\end{array}$ & $\begin{array}{l}\text { A formal } \\
\text { mechanism that } \\
\text { legitimises and } \\
\text { invites family } \\
\text { involvement }\end{array}$ & + & $\begin{array}{l}\text { means smaller groups of staff } \\
\text { of 'good fit' (with the } \\
\text { philosophy of the care } \\
\text { environment), with regular } \\
\text { and ongoing contact with a } \\
\text { group of residents and } \\
\text { relatives have a recognised } \\
\text { role as the resident's advocate }\end{array}$ & $\begin{array}{l}\text { and this creates a sense } \\
\text { of shared endeavour and } \\
\text { mutual respect, } \\
\text { promoting meaningful, } \\
\text { reciprocal, relationships } \\
\text { between staff, family and } \\
\text { residents }\end{array}$ & $=$ & $\begin{array}{l}\text { which leads to greater } \\
\text { personalisation of care }\end{array}$ & $\begin{array}{l}15 \text { studies contributed to } \\
\text { context-mechanism-outcome } \\
\text { configuration } 2 \text { : interview } \\
\text { and/or focus groups }(n=8) \text {, } \\
\text { cross-sectional }(n=1) \text {, case } \\
\text { study }(n=2) \text {, and literature } \\
\text { review }(n=4) \text {. }\end{array}$ \\
\hline $\begin{array}{l}\text { Theory 3: } \\
\text { Reciprocity } \\
\text { amongst } \\
\text { teams }\end{array}$ & $\begin{array}{l}\text { Visible, unit level } \\
\text { supervisors who } \\
\text { minimise conflict } \\
\text { and role model } \\
\text { behaviours that } \\
\text { promote team } \\
\text { relationships }\end{array}$ & + & $\begin{array}{l}\text { ensure open communication } \\
\text { and information sharing } \\
\text { between regular core groups } \\
\text { of staff of an appropriate skill } \\
\text { mix (care staff, senior care } \\
\text { staff, Licensed Practical Nurses } \\
\text { or Nursing Associates, and } \\
\text { Registered Nurses) to meet } \\
\text { residents' needs, working most } \\
\text { shifts on the same unit }\end{array}$ & $\begin{array}{l}\text { and this leads to } \\
\text { enhanced relationships } \\
\text { and creates reciprocity } \\
\text { within teams }\end{array}$ & $=$ & $\begin{array}{l}\text { with staff drawing on } \\
\text { each other's knowledge } \\
\text { and skills to promote } \\
\text { individualised care for } \\
\text { residents and better team } \\
\text { working }\end{array}$ & $\begin{array}{l}33 \text { studies contributed to } \\
\text { context-mechanism-outcome } \\
\text { configuration } 3 \text { : interview } \\
\text { and/or focus groups }(n=13) \text {, } \\
\text { cross-sectional }(n=8), \text { case } \\
\text { study }(n=5) \text {, literature review } \\
(n=2) \text {, ethnography }(n=2) \text {, } \\
\text { mixed methods }(n=2) \text {, and } \\
\text { RCT }(n=1) \text {. }\end{array}$ \\
\hline $\begin{array}{l}\text { Theory 4: } \\
\text { Autonomy } \\
\text { in everyday } \\
\text { work }\end{array}$ & $\begin{array}{l}\text { When staff are } \\
\text { treated as expert } \\
\text { partners in care } \\
\text { with a recognised } \\
\text { role as the } \\
\text { resident's advocate }\end{array}$ & + & $\begin{array}{l}\text { then a core group of staff of } \\
\text { 'good fit' (with the philosophy } \\
\text { of the care environment) have } \\
\text { regular and ongoing contact } \\
\text { with a group of } \\
\text { residents/relatives and other } \\
\text { staff, acquire the skills, } \\
\text { knowledge and experience to } \\
\text { understand what is expected } \\
\text { of them }\end{array}$ & $\begin{array}{l}\text { which leads to a greater } \\
\text { sense of autonomy in } \\
\text { their role and confidence } \\
\text { in their judgements, } \\
\text { decision making and } \\
\text { problem solving within } \\
\text { the boundaries of their } \\
\text { role }\end{array}$ & $=$ & $\begin{array}{l}\text { so that care that is timely } \\
\text { and individualised, } \\
\text { enhanced job satisfaction, } \\
\text { and efficient use of the } \\
\text { capacities and } \\
\text { capabilities of the wider } \\
\text { team }\end{array}$ & $\begin{array}{l}20 \text { studies contributed to } \\
\text { context-mechanism-outcome } \\
\text { configuration } 4 \text { : interview } \\
\text { and/or focus groups }(n=6) \text {, } \\
\text { cross-sectional }(n=6) \text {, case } \\
\text { study }(n=2) \text {, literature review } \\
(n=3), \text { ethnography }(n=1) \text {, } \\
\text { RCT }(n=1) \text {, and mixed } \\
\text { methods }(n=1) \text {. }\end{array}$ \\
\hline $\begin{array}{l}\text { Theory 5: } \\
\text { Reward and } \\
\text { recognition }\end{array}$ & $\begin{array}{l}\text { Employer and } \\
\text { manager } \\
\text { recognition and } \\
\text { reward of staff }\end{array}$ & + & $\begin{array}{l}\text { creates the opportunity for } \\
\text { personal and professional } \\
\text { development, }\end{array}$ & $\begin{array}{l}\text { which enhances the } \\
\text { perceived capabilities of } \\
\text { staff, promoting in-role } \\
\text { satisfaction and } \\
\text { motivation }\end{array}$ & $=$ & $\begin{array}{l}\text { which leads to increased } \\
\text { staff commitment and } \\
\text { intention to stay in post, } \\
\text { and care quality } \\
\text { promoting behaviours }\end{array}$ & $\begin{array}{l}20 \text { studies contributed to } \\
\text { context-mechanism-outcome } \\
\text { configuration } 5 \text { : interview } \\
\text { and/or focus groups }(n=7), \\
\text { cross-sectional }(n=6) \text {, case } \\
\text { study }(n=2) \text {, literature review } \\
(n=2), \text { ethnography }(n=1), \\
\text { pre and post-test intervention } \\
(n=1), \text { and mixed methods } \\
(n=1) \text {. }\end{array}$ \\
\hline $\begin{array}{l}\text { Theory 6: } \\
\text { Cultural } \\
\text { competence }\end{array}$ & $\begin{array}{l}\text { Organisations } \\
\text { endorsing and } \\
\text { facilitating } \\
\text { culturally } \\
\text { appropriate } \\
\text { interactions } \\
\text { between staff and } \\
\text { residents }\end{array}$ & & $\begin{array}{l}\text { create opportunities for staff } \\
\text { to adapt care to the needs of } \\
\text { all residents }\end{array}$ & $\begin{array}{l}\text { creating a sense of } \\
\text { shared mutual respect }\end{array}$ & & $\begin{array}{l}\text { resulting in culturally } \\
\text { appropriate resident care }\end{array}$ & $\begin{array}{l}10 \text { studies contributed to } \\
\text { context-mechanism-outcome } \\
\text { configuration } 6 \text { : interview } \\
\text { and/or focus groups }(n=8) \text {, } \\
\text { literature review }(n=1) \text {, and } \\
\text { ethnography }(n=1) \text {. }\end{array}$ \\
\hline
\end{tabular}

and values (mechanism - resource). This promotes meaningful reciprocal relationships between staff and residents (mechanism - response), leading to development of empathy amongst staff and more individual needs and preferences of residents being met (outcome).

Philosophies of care promoting relationships between staff and residents promote staff behaviours that foster individualised resident care (Forbes-Thompson et al., 2007; Cohen-Mansfield and Parpura-Gill, 2008; Gittell et al., 2008; Andre et al., 2014; Lyons, 2010; Bennett et al., 2015; Edvardsson et al., 2011). Philosophies should include an explicit care-focused mission statement (Forbes-Thompson et al., 2007; Andre et al., 2014; Anderson et al., 2014), clearly articulated and enacted through the everyday be- haviours of managers/supervisors (Forbes-Thompson et al., 2007; Cohen-Mansfield and Parpura-Gill, 2008; Andre et al., 2014; Lyons, 2010; Casey et al., 2011) - leadership elements that make up the context for this context-mechanism-outcome configuration.

Philosophies should go beyond assisting residents with physical tasks, and address residents' social and emotional needs through relationships (Lyons, 2010; Bennett et al., 2015). To be effective, work needs to be organised around such philosophies (Bennett et al., 2015; Edvardsson et al., 2011; Casey et al., 2011). For example, a core number of staff who are a 'good fit' with the philosophy of the care environment, who engage consistently with the same group of residents and with sufficient resources will better meet residents' needs and preferences 
(Verbeek et al., 2009; Eika et al., 2015; Nakrem, 2015; Rantz et al., 2004; Vermeerbergen et al., 2017; Brown Wilson, 2009).

Whilst hard to articulate, staff who are a 'good fit' with the philosophy of the care environment, were those that actively valued older people (Eldh et al., 2016; Bennett et al., 2015; Watson, 2019; Colomer and de Vries, 2016; Carpenter and Thompson, 2008; Skovdahl et al., 2003; Vassba et al., 2019; Barry et al., 2005; Carryer et al., 2010; Cherry et al., 2007): displaying or willing to learn empathy, compassion and kindness (Eldh et al., 2016; Bennett et al., 2015; Brown Wilson, 2009; Colomer and de Vries, 2016; Carpenter and Thompson, 2008; Bourgeault et al., 2010; Fläckman et al., 2009; Adra et al., 2015; Backhaus et al., 2018; Fossey et al., 2019; Hunt et al., 2014) and enacting these attributes through behaviours; performing duties beyond the bare minimum specified in contracts, helping others (Eldh et al., 2016; Bennett et al., 2015; Colomer and de Vries, 2016; Carpenter and Thompson, 2008) and working well with co-workers (Brown Wilson, 2009). This articulation of 'good fit' (with the philosophy of the care environment) is used in other context-mechanismoutcome configurations. Sufficient staff subscribing and enacting the philosophy meant it was reinforced, sustained and relationships developed (Brown Wilson, 2009; Watson, 2019; Barry et al., 2005).

Cross sectional (Spilsbury et al., 2011) and longitudinal studies (Backhaus and V.H., 2014; Backhaus et al., 2018) were inconsistent and contradictory, but revealed no critical number of staff. Numbers varied from 5-15 residents per staff member (Nakrem, 2015; Rantz et al., 2004; Vermeerbergen et al., 2017; Verbeek et al., 2009). Relative criteria were more useful: sufficient staff for timely care, such as avoiding residents crying out for help with no care workers around to notice (Cohen-Mansfield and ParpuraGill, 2008), and consistent staff with regular contact with a group of residents and families (Powell et al., 2018). Small groups of linked residents and staff promoted familiarity, communication and a familial environment for cultivating relationships (Nakrem, 2015; Vermeerbergen et al., 2017; Knopp-Sihota et al., 2015) with more time for residents, families (Powell et al., 2018) and co-workers (Vermeerbergen et al., 2017; Knopp-Sihota et al., 2015; Eika et al., 2015a).

Managerial behaviours encouraged relationship building (Forbes-Thompson et al., 2007; Cohen-Mansfield and ParpuraGill, 2008; Anderson et al., 2014): clearly communicating role expectations and responsibilities (Cohen-Mansfield and ParpuraGill, 2008; Anderson et al., 2014; Brown Wilson, 2009; Karsh et al., 2005; Kjøs et al., 2010); reinforcing individual staff contribution to collective care (Bennett et al., 2015; Anderson et al., 2014; Fläckman et al., 2009); physically helping out with resident needs and supporting staff (Forbes-Thompson et al., 2007; Anderson et al., 2014; McGilton et al., 2014; Swagerty et al., 2005; Scalzi et al., 2006); actively listening to staff, resident and families' concerns (Forbes-Thompson et al., 2007; Gittell et al., 2008; Anderson et al., 2014); and openly discussing challenges faced (Forbes-Thompson et al., 2007; Gittell et al., 2008; Lyons, 2010; Casey et al., 2011; McGilton et al., 2014; Swagerty et al., 2005; Scalzi et al., 2006; Leedahl et al., 2015).

Staff that feel supported, valued and with [managerial] 'permission' to prioritise residents' needs adapt and adopt behaviours that foster expression of residents' preferences whilst providing care (Bennett et al., 2015; Casey et al., 2011; Skovdahl et al., 2003) and experimentation of novel ways of engaging residents (Brown Wilson, 2009; Mallidou et al., 2013; Abbott et al., 2016). A relationships-focus enables greater appropriateness in behaviours given resident preferences (Eldh et al., 2016; ForbesThompson et al., 2007; Bennett et al., 2015; Colomer and de Vries, 2016; Abbott et al., 2016; Vandrevala et al., 2017; Kontos et al., 2010). Strategies employed included associating res- idents' stories to their own experiences, stimulating empathy and taking more responsibility for putting 'learning' (about individual residents) into practice (Eldh et al., 2016; Carpenter and Thompson, 2008; Kontos et al., 2010). Unsupported staff provided less support to colleagues (Casey et al., 2011), weakening the generative mechanisms behind quality.

Developing close bonds with residents is not without risks: relationships developed over time can increase the emotional burden of care (Carpenter and Thompson, 2008; Vandrevala et al., 2017; Jones and Moyle, 2016), feelings of helplessness and distress when unable to reduce suffering (Bennett et al., 2015); not always mitigated by caring experience (Vandrevala et al., 2017). Accordingly, some workplaces discouraged relationship-building with residents (Skovdahl et al., 2003; Jones and Moyle, 2016) to reduce the emotional burden for staff (Casey et al., 2011; Vandrevala et al., 2017; Jones and Moyle, 2016).

\subsection{Context-mechanism-outcome configuration 2: expert families}

Legitimising family involvement in care using a formal mechanism in the long-term care facility that invites their involvement (context), means smaller groups of staff of 'good fit' with the philosophy of the care environment, with regular and ongoing contact with a group of residents and relatives have a recognised role as the resident's advocate and expert (mechanism - resource). This creates a sense of shared endeavour and mutual respect, promoting meaningful, reciprocal, relationships between staff, family and residents (mechanism - response) and greater personalisation of care (outcome).

Family members are an important and valuable source of information and understanding for residents' needs and preferences (Cohen-Mansfield and Parpura-Gill, 2008; Brown Wilson, 2009; Adra et al., 2015; Backhaus et al., 2018; Hunt et al., 2014; Scalzi et al., 2006; Puurveen et al., 2018; Chenoweth et al., 2015). Staff engagement with family members - if desired - leads to family acting as experts in their relative's care (Hunt et al., 2014; Swagerty et al., 2005; Puurveen et al., 2018; Chenoweth et al., 2015). In a philosophically and behaviourally supportive context, these roles positively influence staff behaviours and create opportunities for relationship centred care (CohenMansfield and Parpura-Gill, 2008; Adra et al., 2015; Irving, 2015; Gjerberg et al., 2010) - especially for residents living with dementia (Puurveen et al., 2018).

Family involvement is legitimised via formal mechanisms for involvement. This also encourages relationship building (Powell et al., 2018; Puurveen et al., 2018; Irving, 2015; Bauer et al., 2014) built around 'informing staff' and 'consulting with staff' through to 'co-deciding with staff' (Puurveen et al., 2018). Mechanisms for meaningful participation include: invitations to care planning meetings (Hunt et al., 2014; Puurveen et al., 2018; Irving, 2015; Tjia et al., 2017), support groups for family members (Bauer et al., 2014), formal introductions to staff members at the facility (Puurveen et al., 2018; Irving, 2015), and regular family information meetings (Irving, 2015; Tjia et al., 2017).

Relationships between staff and family members should be reciprocal and act as a vehicle for sharing information about residents (Bennett et al., 2015; Adra et al., 2015; R. Backhaus et al., 2018; Powell et al., 2018; Swagerty et al., 2005; Puurveen et al., 2018; Irving, 2015), their preferences and other personal information for informed care (Adra et al., 2015; Backhaus et al., 2018; Puurveen et al., 2018; Chenoweth et al., 2015) and care planning (Puurveen et al., 2018). Practical manifestations can be seen in staff avoiding foods that a resident dislikes and using personal belongings to create homely environments (Adra et al., 2015; Swagerty et al., 2005). Family may demonstrate successful behavioural strategies and interpretation with residents 
(Bennett et al., 2015; Puurveen et al., 2018; Bauer et al., 2014). In turn, staff feel rewarded from positive relationships with families (Bennett et al., 2015).

Establishing relationships with family members takes time (Cohen-Mansfield and Parpura-Gill, 2008; Bennett et al., 2015; Brown Wilson, 2009; Adra et al., 2015; Backhaus et al., 2018; Irving, 2015). Once established, communicating care plan changes (Irving, 2015), health (Bennett et al., 2015), and participation in activities can be sustained (Adra et al., 2015), generating a greater sense of shared caring responsibilities and mutual respect (Bennett et al., 2015; Adra et al., 2015; Swagerty et al., 2005; Scalzi et al., 2006).

Risks for staff associated with greater familial involvement include feelings of stress and anxiety arising from unrealistic demands and expectations on care provided (Cohen-Mansfield and Parpura-Gill, 2008; Bennett et al., 2015; Jones and Moyle, 2016; Puurveen et al., 2018; Gjerberg et al., 2010) or an unwillingness from family to accept a resident's deterioration (Jones and Moyle, 2016) or challenging behaviours (Bennett et al., 2015). One consequence are negative feedback loops of poor staff experience and negative attitudes towards families, diminishing recognition of continued importance of staff-family relationships (Cohen-Mansfield and Parpura-Gill, 2008; Puurveen et al., 2018; Gjerberg et al., 2010), and subsequent relationship breakdown (Cohen-Mansfield and Parpura-Gill, 2008; Bennett et al., 2015; Jones and Moyle, 2016; Gjerberg et al., 2010).

\subsection{Context-mechanism-outcome configuration 3: team reciprocity}

Visible, unit level supervisors who minimise conflict and role model behaviours promoting team relationships (context), ensure open communication and information sharing between regular core groups of staff of an appropriate skill mix (care staff, senior care staff, Licensed Practical Nurses or Nursing Associates, and Registered Nurses) to meet residents' needs, working most shifts on the same unit (mechanism resource). Enhanced relationships create reciprocity within teams (mechanism response), with staff drawing on each other's knowledge and skills to promote individualised care for residents and better team working (outcome).

Companionship is important in care work; being seen, needed and supported by reciprocating teammates provides satisfaction and meaning in work (Skovdahl et al., 2003; Vassba et al., 2019). Expressions of reciprocity included, "we depend on each other" (Skovdahl et al., 2003; Swagerty et al., 2005), "show respect for one another" (Anderson et al., 2014; Scalzi et al., 2006), "we take turns"[28], and "we are a part of each other's decision making" (Anderson et al., 2014). Sometimes reciprocity was implicit in team work (Lyons, 2010), meaningful relationships with colleagues (Bennett et al., 2015; McGilton et al., 2014), shared values (Gittell et al., 2008; Lyons, 2010; Vassba et al., 2019; Kjøs et al., 2010; Swagerty et al., 2005), mutual respect (Gittell et al., 2008), a mutual understanding of each other's work (Bennett et al., 2015; McGilton et al., 2014), strong group relations (Andre et al., 2014), and unified commitment (Andre et al., 2014; Skovdahl et al., 2003; Scott-Cawiezell et al., 2005). Whether explicit or implicit, reciprocity was linked with information exchange and the ability to draw on each other's knowledge and skills to promote individualised care and enhance quality (Forbes-Thompson et al., 2007; Gittell et al., 2008; Andre et al., 2014; Lyons, 2010; Bennett et al., 2015; Anderson et al., 2014; Brown Wilson, 2009; Skovdahl et al., 2003; Kjøs et al., 2010; McGilton et al., 2014; Swagerty et al., 2005; Scalzi et al., 2006; Estabrooks et al., 2011; Kuo et al., 2008). Teams with high degrees of reciprocity were more open to advice seeking and collaborating (Vassba et al., 2019; Kuo et al., 2008).

Leaders - at unit level - exhibited various behaviours designed to foster reciprocity:
- Clearly communicating expectations of staff, ways of working and their behaviours (Forbes-Thompson et al., 2007; Anderson et al., 2014; Brown Wilson, 2009; Kjøs et al., 2010);

- Promoting shared goals and mutual respect (Gittell et al., 2008; Kjøs et al., 2010);

- Helping out on the long-term care facility floor (ForbesThompson et al., 2007; Anderson et al., 2014; Swagerty et al., 2005; Scalzi et al., 2006);

- Holding regular meetings inclusive of all staff (ForbesThompson et al., 2007; Anderson et al., 2014; Kjøs et al., 2010);

- Openly discussing and resolving problems as a team (ForbesThompson et al., 2007; Gittell et al., 2008; Anderson et al., 2014);

- Flexible working structures for staff (Lyons, 2010; Edvardsson et al., 2011; Casey et al., 2011; Brown Wilson, 2009; McGilton et al., 2014; Scalzi et al., 2006);

- Encouraging the sharing of ideas (Forbes-Thompson et al., 2007; Gittell et al., 2008; Lyons, 2010; Anderson et al., 2014; McGilton et al., 2014);

- Bringing staff together as a close-knit group bound together by common interests and experiences (Gittell et al., 2008; Kjøs et al., 2010; Swagerty et al., 2005);

- Regular staff supervision (Forbes-Thompson et al., 2007; Lyons, 2010; McGilton et al., 2014).

Role experience was a modifier of reciprocity reinforcing behaviours. Experienced staff often used reciprocal behaviours to build confidence with less experienced/confident staff (Casey et al., 2011; Brown Wilson, 2009; Colomer and de Vries, 2016; Vassba et al., 2019; Barry et al., 2005; Jack et al., 2019; Rapaport et al., 2017; Zeller et al., 2014; Gillham et al., 2018; Yeatts and Cready, 2007). Such behaviours were nested in relationships built on open communication and respect for the less experienced (Gillham et al., 2018; Cammer et al., 2014). Managerial support meant experienced staff shared greater knowledge and experiences (Casey et al., 2011; Colomer and de Vries, 2016; Skovdahl et al., 2003; Zeller et al., 2014; Rokstad et al., 2015); especially amongst staff caring for people living with dementia (Skovdahl et al., 2003; Fossey et al., 2019; Chenoweth et al., 2015; Chenoweth et al., 2014). Units that discouraged co-worker relationships often lacked team reciprocity (Jones and Moyle, 2016), and of poorer quality. Unit-level supervisors that minimise conflict and role model relationship building behaviours provide the context in this context-mechanism-outcome configuration.

Role modelling and reciprocity do not always co-exist. Negative outcomes include complacent staff generating and sustaining power imbalances or bullying - particularly in chronically short-staffed homes. Examples included ignoring or excluding team members or withholding information about resident care (Tong et al., 2017). Understaffed care teams have higher workloads, less time available for interpersonal discussions and less time for defusing frustrations, leading to conflict (Tong et al., 2017). Effective leadership and management is crucial for minimising such unintended outcomes (Eika et al., 2015a; Jones and Moyle, 2016; Yeatts and Cready, 2007; Tong et al., 2017).

\subsection{Context-mechanism-outcome configuration 4: autonomy in everyday work}

When staff are treated as expert partners in care with a recognised role as the resident's advocate (context), then a core group of staff of 'good fit' (with the philosophy of the care environment) with regular and ongoing contact with a group of residents/relatives and other staff, acquire the skills, knowledge and experience of what is expected of them (mechanism resource). This leads to greater sense of autonomy in role and confidence in 
their judgements, decision making and problem solving within the boundaries of their role (mechanism response). The result is care that is timely and individualised, enhanced job satisfaction, and efficient use of the capacities and capabilities of the wider team (outcome).

Greater perceived autonomy means greater staff engagement with work (Cohen-Mansfield and Parpura-Gill, 2008; Bennett et al., 2015; Karsh et al., 2005; Jacobsen et al., 2018) or role empowerment (Cohen-Mansfield and Parpura-Gill, 2008; Kuo et al., 2008; Yeatts and Cready, 2007; Caspar and O'Rourke, 2008). Autonomy is a positive and necessary feature of delivering individualised resident care (Cohen-Mansfield and Parpura-Gill, 2008; Bennett et al., 2015; Hunt et al., 2014; Jacobsen et al., 2018; Caspar and O'Rourke, 2008). Flexibility in staff responses to needs is highly valued, leading to higher perceived quality amongst family and residents (Andre et al., 2014; Chenoweth et al., 2015; Jacobsen et al., 2018). Increasing autonomy is easier in smaller teams of staff, working consistently with the same group of residents and colleagues (Vermeerbergen et al., 2017).

Autonomy, behavioural enactment, and leadership co-exist in a positive feedback loop. Collective agreement resulting from reciprocity, strengthens collective knowledge and shared values/mission, which in turn gives staff greater confidence to act independently (Vassba et al., 2019). Shared values are vital to developing professional values and integrity, refining staff skills, supporting further learning and development of skills and satisfaction with work (Vassba et al., 2019). These leadership elements constitute the context in this context-mechanism-outcome configuration. In such long-term care facilities, management practices foster staff with the skills, knowledge (Cohen-Mansfield and Parpura-Gill, 2008), opportunity (Forbes-Thompson et al., 2007) and confidence to become autonomous workers (Chenoweth et al., 2014).

Staff exhibit active autonomy in resident care in various ways that promote quality of care: reporting they are involved in care planning (Eldh et al., 2016; Cohen-Mansfield and ParpuraGill, 2008; Jacobsen et al., 2018; Caspar and O'Rourke, 2008), asking for advice (Eldh et al., 2016; Cohen-Mansfield and ParpuraGill, 2008), being encouraged to innovate with different ways of providing care or undertaking work (Cohen-Mansfield and ParpuraGill, 2008; Bennett et al., 2015; Karsh et al., 2005; McGilton et al., 2014), meeting residents' needs flexibly (Skovdahl et al., 2003; McGilton et al., 2014) and being consulted for their views, ideas and opinions (Cohen-Mansfield and Parpura-Gill, 2008; Nakrem, 2015; Carpenter and Thompson, 2008; Kuo et al., 2008; Caspar and O'Rourke, 2008; Rondeau and Wagar, 2006), and feeling valued for such input (Eldh et al., 2016; Cohen-Mansfield and Parpura-Gill, 2008; Barry et al., 2005; Kuo et al., 2008).

Staff who see themselves as equal partners in care experienced a sense of shared responsibility (Eldh et al., 2016) and mutual respect (Cohen-Mansfield and Parpura-Gill, 2008). Staff capacities and capabilities when recognised and used efficiently result in work geared to meeting individual resident needs, rather than institutional routines (Eldh et al., 2016; Cohen-Mansfield and Parpura-Gill, 2008; Carpenter and Thompson, 2008; Barry et al., 2005; McGilton et al., 2014; Jacobsen et al., 2018; Caspar and O'Rourke, 2008). Autonomy allowed staff time to 'do the little extra's' (Vassba et al., 2019). As a result, staff were more likely to be independent in their work (Karsh et al., 2005), considered themselves able to make decisions (Kuo et al., 2008; Caspar and O'Rourke, 2008; Rondeau and Wagar, 2006), and shared work (Cohen-Mansfield and Parpura-Gill, 2008; Barry et al., 2005; Karsh et al., 2005). A high degree of flexibility in their work plans makes it easier for staff to collaborate and consult with each other in short informal meetings and, further, to support and help each other during the shift (Vassba et al., 2019).

\subsection{Context-mechanism-outcome configuration 5: reward and} recognition

Employer and manager recognition and reward of staff (context) creates the opportunity for personal and professional development (mechanism resource), enhancing the perceived capabilities of staff, promoting in-role satisfaction and motivation (mechanism resources), and increasing staff commitment and intention to stay in post, and care quality promoting behaviours (outcome).

Rewarding and recognising staff influenced how staff felt about their work and shaped behaviours. Reward and recognition happen formally and informally. Formal endorsement arises from:

- the senior executive team (organisational level) and/or longterm care facility leaders (Caspar and O'Rourke, 2008);

- the organisational mission statement (placing as much value on staff as residents) (Eldh et al., 2016; Forbes-Thompson et al., 2007; Carpenter and Thompson, 2008);

- training and education (Eldh et al., 2016; Cohen-Mansfield and Parpura-Gill, 2008; Andre et al., 2014; Edvardsson et al., 2011; Carryer et al., 2010; Karsh et al., 2005; Rokstad et al., 2015; Caspar and O'Rourke, 2008; Cramer et al., 2014; EthertonBeer et al., 2013);

- career advancement opportunities (Bishop et al., 2008; Eldh et al., 2016; Edvardsson et al., 2011; Carryer et al., 2010; Caspar and O’Rourke, 2008; Cramer et al., 2014);

- adequate pay (Bishop et al., 2008; Cohen-Mansfield and Parpura-Gill, 2008);

- coaching and mentoring (Bishop et al., 2008; ForbesThompson et al., 2007; Anderson et al., 2014; Carpenter and Thompson, 2008; Carryer et al., 2010; Cherry et al., 2007); and

- involvement in decision-making about resident care for the resident's they knew well (Eldh et al., 2016; Carpenter and Thompson, 2008; Cramer et al., 2014).

Surprisingly, little evidence exists regarding the influence of pay on perceptions of work and staff behaviours.

Informally, recognition can be:

- managers addressing staff by first or preferred name and praising staff for their contribution (Forbes-Thompson et al., 2007; Cohen-Mansfield and Parpura-Gill, 2008; Anderson et al., 2014; Fläckman et al., 2009; Caspar and O'Rourke, 2008);

- utilising the unique knowledge staff have about individual residents by asking them for their opinions on how best to support the resident population (Cohen-Mansfield and ParpuraGill, 2008; Anderson et al., 2014);

- managers 'pitching in' with the day to day work, such as making beds and assisting at meal times, to support staff (ForbesThompson et al., 2007; Anderson et al., 2014); and

- providing emotional support for any anxieties staff experience as a result of providing care (Casey et al., 2011; Verbeek et al., 2009).

Rewards are wide ranging but included offering small gifts or arranging social gatherings to demonstrate appreciation for a job well done (Forbes-Thompson et al., 2007; Kjøs et al., 2010). The investment in staff through rewards and recognition had a positive impact on how staff felt about their work, enhanced staffmanager relationships, and led to behaviours that promoted quality in the long-term care facility and for the benefit of residents (Eldh et al., 2016; Forbes-Thompson et al., 2007; Andre et al., 2014; Carpenter and Thompson, 2008; Barry et al., 2005; Fläckman et al., 2009; Verbeek et al., 2009; Caspar and O’Rourke, 2008). 
3.6. Context-mechanism-outcome configuration 6: cultural competence

Organisations endorsing and facilitating culturally appropriate interactions between staff and residents (context), create opportunities for staff to adapt care to the needs of all residents (mechanism resource), creating a sense of shared mutual respect (mechanism response) and culturally appropriate resident care (outcome).

Cultural competence, the ability to understand, communicate and effectively interact with people of different cultures, helps staff meet residents' needs and promote quality of care and life (CohenMansfield and Parpura-Gill, 2008; Casey et al., 2011; Bauer et al., 2014; Hafford-Letchfield et al., 2018). Manifestations of cultural competence included:

- Employing staff from different backgrounds, which was identified as valuable for promoting cross-cultural relationships with residents, family and co-workers (Cohen-Mansfield and Parpura-Gill, 2008; Casey et al., 2011; Bourgeault et al., 2010; Kontos et al., 2010; Bauer et al., 2014; Gillham et al., 2018).

- Respecting religious beliefs (Casey et al., 2011; Kontos et al., 2010; Gillham et al., 2018), cultural norms (CohenMansfield and Parpura-Gill, 2008; Watson, 2019; Bourgeault et al., 2010; Gillham et al., 2018; Lea et al., 2017), and sexual orientation (Hafford-Letchfield et al., 2018; Donaldson and Vacha-Haase, 2016) made a positive difference to daily lives of residents (Cohen-Mansfield and ParpuraGill, 2008; Casey et al., 2011; Watson, 2019; Bourgeault et al., 2010; Gillham et al., 2018).

- Knowing how to provide culturally appropriate personal care - such as meal preparation (Bourgeault et al., 2010; Lea et al., 2017), honouring rituals (Cohen-Mansfield and Parpura-Gill, 2008; Casey et al., 2011; Bourgeault et al., 2010; Kontos et al., 2010), greeting residents using their first language (Gillham et al., 2018), being in tune with local dialects (Sion et al., 2020), touching a resident in a culturally appropriate manner (Cohen-Mansfield and Parpura-Gill, 2008; Gillham et al., 2018), and/ or using appropriate non-verbal communication (Casey et al., 2011; Bourgeault et al., 2010; Bauer et al., 2014; Gillham et al., 2018).

These factors all helped develop and maintain (cross-cultural) relationships between staff and residents (Cohen-Mansfield and Parpura-Gill, 2008; Bourgeault et al., 2010; Gillham et al., 2018).

Quality promoting relationships are hindered (Bauer et al., 2014; Gillham et al., 2018) when staff experience discriminatory behaviour from residents; for example, verbal abuse on the basis of skin colour (Bourgeault et al., 2010), accent (Bourgeault et al., 2010), sexual orientation (HaffordLetchfield et al., 2018; Donaldson and Vacha-Haase, 2016), and language difficulties (Bourgeault et al., 2010; Chenoweth et al., 2015; Bauer et al., 2014; Kuo et al., 2008; Gillham et al., 2018; Donaldson and Vacha-Haase, 2016). Management intervention is essential to repair relationships (Casey et al., 2011).

Cultural competence is developed on the job (Casey et al., 2011; Chenoweth et al., 2015; Gillham et al., 2018; HaffordLetchfield et al., 2018) and reinforced through team reciprocity (Bourgeault et al., 2010; Gillham et al., 2018), exhibited as respect and tolerance of each other's cultures, effective crosscultural communication and learning (Gillham et al., 2018; Donaldson and Vacha-Haase, 2016), and promotion of relationships between co-workers (Bourgeault et al., 2010; Chenoweth et al., 2015).

\section{Discussion}

Our realist review outlined six theoretical propositions (context-mechanism-outcome configurations) as necessary conditions for behaviour systems that influence quality as experienced by long-term care facility residents. Context-mechanism-outcome configurations build on previous reviews examining staff numbers and mix and the broad and possibly unhelpful conclusion that some numbers and models of deployment have some impact on some clinical indicators of quality; a conclusion borne of scant and often low quality evidence (Spilsbury et al., 2011; Backhaus et al. 2014; Backhaus et al., 2018). Our explanatory framework has been 'sense-checked' with those living, working (or working with)and visiting long-term care facilities.

As Fig. 3 illustrates, our six context-mechanism-outcome configurations connect and impact on each other. However, one thread ran through all of them: each context-mechanism-outcome configuration required effective leadership behaviours (at all levels) to trigger the effective use of resources (mechanism), that cultivated the relationships (mechanism response) required for staff to behave in ways that promote quality (outcome).

A clear organisational philosophy of care, endorsed and enacted by the long-term care facility manager supports relationship building between staff, residents and relatives. This role modelling influences other leaders in the long-term care facility to also enact and support these relationship building behaviours across the unit and/ or facility (depending on their level of leadership). Good working relationships support team learning opportunities, rewards and recognition. The way care teams are organised, alongside opportunities for listening and problem solving, are important, provide direction, promote positive behaviours and minimise conflict in the home. Such leadership behaviours are summarised in Table 2.

The 'generative mechanism' underpinning each of our contextmechanism-outcome configurations is relationships. The link between relationships and behaviour to promote quality in health care is well established (Nolan et al., 2004; Nolan et al., 2006; Soklaridis et al., 2016). Whilst relationships are a central component of theories often enacted in social care, such as Person Centred Care (Kitwood, 1997; McCormack and McCance, 2006) and relationship centred care, (Nolan et al., 2004) empirical research is more limited: largely limited to qualitative studies (Watson, 2019; Nolan et al., 2006; Dewar and Nolan, 2013; Owen et al., 2015) that have developed slowly since the genesis of formal theories in the mid-1990s (Tresolini, 1994).

Our findings resonate with other frameworks from an interactionist perspective. Nolan et al. suggest that people, their families and care staff must satisfy the six senses of security, belonging, purpose, continuity, achievement and significance in the context of their relationships to thrive (Nolan et al., 2006). Kitwood (1997) emphasises that upholding the personhood of people living with dementia can only be achieved by upholding the personhood of staff, in the context of a caring organisation which acknowledges, respects and rewards staff contributions (and as acknowledged in our fifth context-mechanism-outcome configuration) (Kitwood, 1997). McCormack et al. (McCormack et al., 2012; McCormack and McCance, 2010) further support this by placing no distinction between the resident, the family (or friends) and care staff. Indeed, they argue that the only way quality can be experienced by residents and families is for care staff to experience respect and recognition for their personhood and for caring cultures to be created. These aspects are incorporated in our programme theories. Our review is the first to synthesise empirical research into why relationship centred care in long-term care facilities might work, for who and under what circumstances, alongside the contexts and mechanisms for influencing these relationships. 


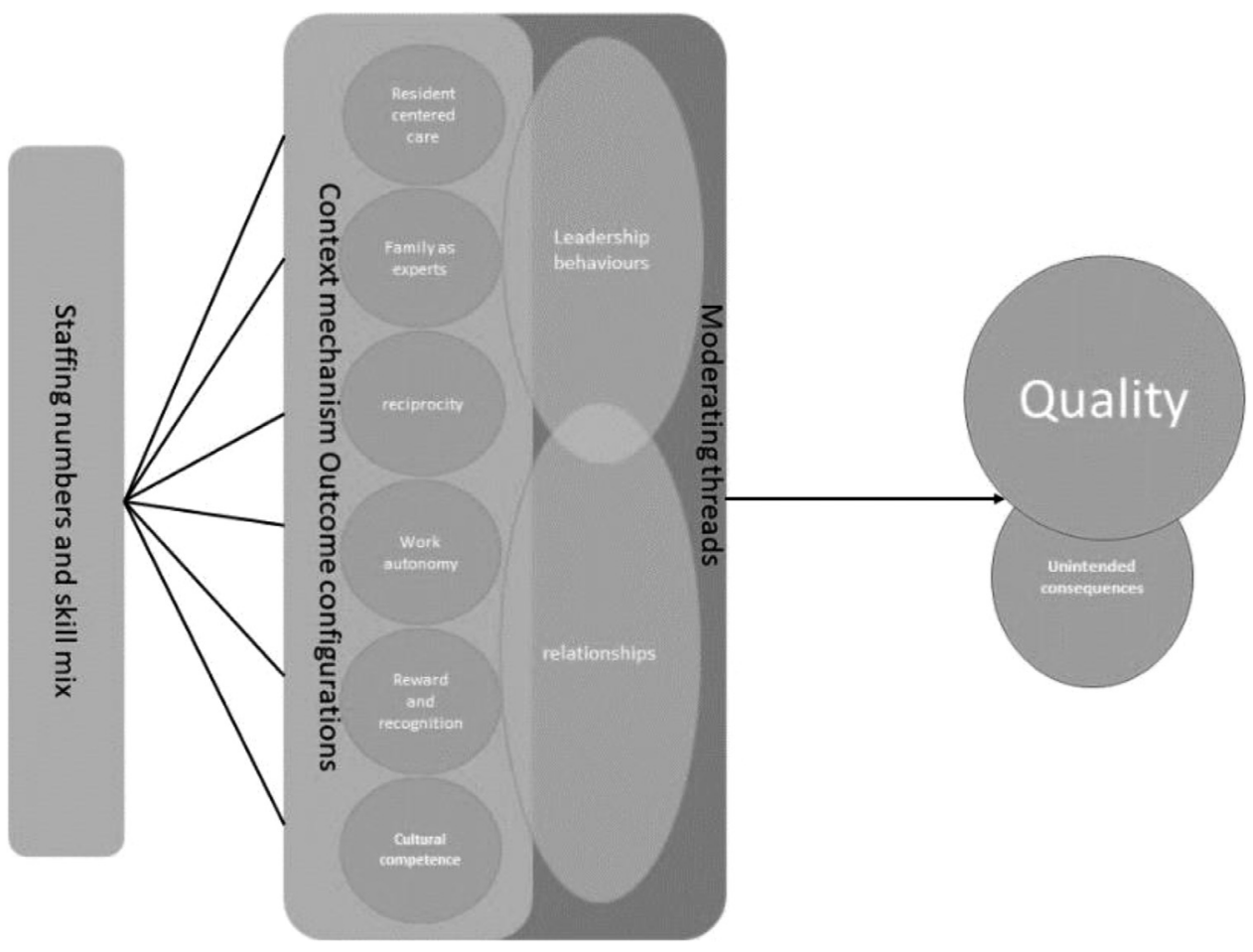

Fig. 3. summary of context-mechanism-outcome configurations.

Our context-mechanism-outcome configurations are presented as drivers for positive relationships underpinning positive staff behaviours. However, they can also introduce and sustain poor staff behaviours and lower quality. Official inquiries and case studies of organisational failures leading to poor quality care (NHS England 2014; The Mid Staffordshire NHS Foundation Trust 2013; Kirkup, 2015; Strandmark et al., 2019; Eitienne, 2014; Butler et al., 2018) often highlight negative cultures within organisations, leadership and bullying, all sustained in part by relationships and unequal distributions of social capital.

Our review highlights sufficient staff numbers as necessary but not sufficient for quality promoting behaviours. Like almost all behavioural aspects of health and social care, staffing (as context) is important. Relationships, as a generative mechanism for quality, were more heavily influenced by leadership rather than simply staff numbers.

Leadership's importance for improving quality in long-term care is well recognised by researchers (Rokstad et al., 2015; Orellana et al., 2017; Penney and Ryan, 2018; Havig et al., 2011; Castle and Decker, 2011), regulators and policy makers (Owen et al., 2015; Care Quality Commission, 2019; Social Care Institute for Excellence 2017; The National Skills Academy for Social Care 2014), and academics (Bowman and Meyer, 2017). Our review suggests: (i) leaders in long-term care are not always the long-term care facility manager; that is, unit level supervisors also play an integral role; (ii) how these leaders operate influences the day-today work and activities of staff in the home; and (iii) that leadership behaviours effectively shape long-term care cultures and relationships required for quality. Effective leadership occurs within and between levels that are connected, setting off chains of events. These events will always appear different in terms of the social actors involved, timescales and ordering, but they occur with sufficient regularity, are theoretically defensible, and thus considered predictable.

Formal models of leadership may be a useful mechanism for homes to enact some of the context-mechanism-outcome con- figurations presented. Transformational leadership (Burns, 1978; Bass, 1985) - 'a form of leadership intended to motivate and inspire followers to pursue higher-order goals through the transformation of followers' attitudes, beliefs, values and behaviours' (100: p543) - has been linked to Person Centred Care Theory (McCormack and McCance, 2006) and is consistent with the leadership style implied by relationship centred care (Nolan et al., 2006). Whilst evidence for transformational leadership in nursing exists (Broom and Marshall, 2010; Dias et al., 2019; Fischer, 2016; Doody and Doody, 2012; Cummings et al., 2018), the very limited evidence from long term care suggests it has the potential to encourage behaviours that promote quality, by empowering staff closest to the delivery of care (Owen et al., 2015). Models such as "transformational leadership" often major on desired outcomes (such as shifts in attitudes, beliefs and behaviours) but lack of outcome definition hinders implementation and evaluation. Leadership and culture interact: culture can be manipulated by leaders (Bate, 2004; Schneider, 1994; Lynch et al., 2018), but may also be created by the actions and reactions of leaders, with leaders in turn shaped by that culture (Bate, 2004; Lynch et al., 2018). Our review highlights the ill-defined nature of leadership and culture in empirical studies of staffing and quality. We have proposed specific leadership behaviours for promoting quality to make the concept more transparent (c.f. Table 2).

\subsection{Review strengths and limitations}

Much of the evidence base informing our review is descriptive, lacks comparison or controls, and is small scale. The lack of comparative research means providers and commissioners seeking to make evidence-informed decisions about which staffing models are likely to be most effective will not find definitive answers.

Limited information on personal characteristics of leaders mean establishing which attributes (i.e. age, gender, level of education, length of service in the home, length of service in care) were most influential is impossible. Descriptions of settings and pivotal con- 
Table 2

Leadership behaviours (at all levels of the organisation) that lead to quality.

A resident centred approach to organising care

- Giving permission' to prioritise residents' needs adapt and adopt behaviours encouraging expression of residents' preferences as part of everyday care i.e. Work is scheduled around individual needs of residents, rather than the routines of long-term care facilities

- Creating smaller teams of staff, who work consistently with the same group of residents and co-workers

\section{Effective communication}

- Clearly communicating expectations of staff, ways of working and their behaviours

- Promoting shared goals and mutual respect

- Actively listening to staff, resident and families' concerns

- Openly discussing the challenges faced in the home, discussing and resolving problems as a team

- Invitations of family to care planning meetings

- Formal introductions between family and staff members at the facility

\section{Promote confidence}

- Reinforcing individual staff contribution to collective care

- Coaching and mentoring

- Encouraging the sharing of ideas

- Involvement in decision-making about resident care for the resident's they knew well

- Increasing perceived autonomy

- Holding regular meetings inclusive of all staff

- Regular family information meetings

\section{Provide practical support}

- Physically helping out with resident needs and supporting staff i.e. pitching in' with the day to day work, such as making beds and assisting at mealtimes, to support staff

- Being visible

\section{Provide emotional support}

- Providing emotional support for anxieties staff experience as a result of providing care

- Bringing staff together as a close-knit group bound together by common interests and experiences

- Support groups for family members

\section{Show recognition}

- The organisational mission statement and the senior executive team (organisational level) placing as much value on staff as residents)

- Flexible working structures for staff

- Addressing staff by first or preferred name and praising staff for their contribution

- Creating opportunities for training and education

- Career advancement opportunities

- Formally inviting family involvement to 'inform staff' and 'consult with staff' through to 'co-deciding with staff'

\section{Encourage diversity}

- Employing staff from different backgrounds, which was identified as valuable for promoting cross-cultural relationships with residents, family and co-workers

- Respecting religious beliefs, cultural norms and sexual orientation.

\section{Box 1}

Working definitions of realist terms.

Context: the conditions constituting the setting for the intervention. Context influences the way resources are perceived to generate outcomes

Mechanism: the resource the intervention provides and the impact it has on the reasoning of staff

Demi-regularity: a semi-predictable pattern of outcomes i.e. frequently reproduced behaviours

Outcome: the expected or unexpected result

Programme Theory: describes how the intervention is expected to generate effects and under what conditions (usually expressed as context-mechanism-outcome configurations)

Context-mechanism-outcome configuration: the unit of analysis used to synthesise across studies to build and refine programme theory

cepts - leadership, culture or quality - were often superficial or poorly described, limiting the explanatory and predictive precision of our programme theory.

A strength of this review is the involvement of relevant stakeholders within the review process. More specifically, we engaged with residents, relatives, staff, providers, commissioners, regulators and policymakers to sense-check, improve explanation and theory development. This promotes relevance of our work for the sector. Another strength of our review is that we were able to use theory to unpack and operationalise concepts such as leadership in context for use in future research. This is the first realist review drawing on international evidence to consider how behaviours influence quality in the sector. The review has, for this first time, moved evidence-based discussion beyond numbers of staff in long term care and the relationship to quality, to a focus on the importance of what they do and how they do it.

\subsection{Implications for future research}

Future research should focus on comparative, theoretically informed studies that systematically extend empirical knowledge and theory. For example, a useful contribution to this field would be understanding the characteristics of leadership at different levels (such as at the organisation, unit, or informal level) and how this impacts quality. There is limited research to evaluate the impact of the relationship centred care model on quality. There may be interventions that could be developed based on our theories that could be tested. To enhance reproducibility and solid testing of theory, such studies should report interventions in structured ways (Hoffmann et al., 2014). Structured reporting enables systematic isolation, manipulation and optimisation of active ingredients. Researchers seeking to improve quality through a focus on changing staffing behaviours may wish to consider the role of international initiatives in optimisation of quality improvement such as Metalab (Grimshaw et al., 2019), that have begun to be deployed in long term care (Ivers et al., 2017). 


\subsection{Implications for practice}

We have demonstrated the importance of leaders for ensuring relationships are central to the organisation of care and staff that are more likely to behave in quality-promoting ways. By highlighting the important role that the facility and unit manager have, as well as informal leaders, in creating relationships, this review provides a platform for those working in, managing, leading, or providing long-term care to consider quality improvement. We have highlighted the contextual factors required to support the nurturing of positive staff behaviours. This requires the support of effective leaders (as described by this review) to create environments that promote quality. Simply increasing staff numbers without considering staff relationships is unlikely to promote quality. While there is little analysis of costs in the included studies, we would argue that the focus on behaviours could be introduced with relatively little cost.

\section{Conclusion}

This is the first review of international literature to offer theory-based explanations of why, how and in what circumstances, staff behaviours promote quality for older people living in longterm care facilities. It shifts the debate from numbers of staff and their relationship to quality indicators toward recognising the ways in which staff influence experiences of care and thus quality. Our findings will be useful for people and organisations making policy and delivering services on the best ways to deploy and support quality in care homes through the most valuable resource for any long-term care facility: its staff.

\section{Declaration of Competing Interest}

The authors declare the following financial interests/personal relationships which may be considered as potential competing interests: CG is NIHR Senior Investigator and receives support from the National Institute of Health Research (NIHR) Applied Research Collaboration East of England (ARC EoE) programme.

\section{Acknowledgments}

We would like to thank our stakeholder groups for their contributions to this review and in particular: Theodore Bacon, Rosemary Cox, Tony Dale, Jenny Hill, and Pamela Phillips. We also acknowledge the input of those that at various points informed the review: our Study Steering Committee, Care Home Manager Advisory Group, David Alldred, Vivienne Birch, Lucy Brown, Anna Cronin de Chavez, Will Fenton, David Griffiths, Heather Gage, Cornell Jackson and Ian Turner.

\section{Funding}

This ongoing project is funded by the National Institute for Health Research (NIHR) Health Services and Delivery Research Programme (project number 15/144/29) and when completed will be published in full in the NIHR Journal Health Services and Delivery Research. Further information available at: https://www.journalslibrary.nihr.ac.uk/programmes/hsdr/1514429/\#/.

\section{Disclaimer}

The views and opinions expressed by authors in this publication are those of the authors and do not necessarily reflect those of the NHS, the NIHR, MRC, CCF, NETSCC, the Health Services and Delivery Research Programme or the Department of Health and Social Care.

\section{Supplementary materials}

Supplementary material associated with this article can be found, in the online version, at doi:10.1016/j.ijnurstu.2021.103905.

\section{References}

Abbott, K.M., Heid, A.R., Van Haitsma, K., 2016. We can't provide season tickets to the opera": staff perceptions of providing preference-based, person-centered care. Clin. Gerontol. 39 (3), 190-209.

Adra, M.G., Hopton, J., Keady, J., 2015. Constructing the meaning of quality of life for residents in care homes in the Lebanon: perspectives of residents, staff and family. J. Older People Nurs. 10 (4), 306-318.

Age UK, 2018. Later Life in the United Kingdom. Age UK, Editor, London.

Anderson, A.R., Issel, M.L., McDaniel, R.R., 2003. Nursing homes as complex adaptive systems: relationship between management practice and resident outcomes. Nurs. Res. 52 (1), 12-21.

Anderson, R.A.T., P., M., Corazzini, K., McDaniel, R.R., Colon-Emeric, C., 2014. Local interaction strategies and capacity for better care in nursing homes: a multiple case study. BMC Health Serv. Res. 14, 244.

Andre, B.S.E., Rannestad, T., Ringdal, G.I., 2014. The impact of work culture on quality of care in nursing homes-a review study. Scand. J. Car. Sc. 28 (3), 449-457.

Backhaus, R., Verbeek, H., van Rossum, E., et al., 2014. Nurse staffing impact on quality of care in nursing homes: a systematic review of longitudinal studies. JAMDA $15(6), 10$.

Backhaus, R., Beerens, H.C., van Rossum, E., et al., 2018a. Rethinking the staff-quality relationship in nursing homes. J Nutr. Health Aging 22 (6), 634-638.

Backhaus, R., Hoek, L., Van Haastregt, J., et al., 2018b. Increasing family inclusion in nursing homes for people with dementia: a literature review. Innovation in Aging 2 (suppl_1), 537.

Barry, T.T., Brannon, D., Mor, V., 2005. Nurse aide empowerment strategies and staff stability: effects on nursing home resident outcomes. Gerontologist 45 (3), 309-317.

Bass, B.M., 1985. Leadership and Performance Beyond Expectations. Free Press, New York.

Bate, S., 2004. Strategies For Cultural Change. Oxford, Butterworth Heinemann.

Bauer, M., Fetherstonhaugh, D, Tarzia, L., Chenco, C., 2014. Staff-family relationships in residential aged care facilities: the views of residents' family members and care staff. J. Appl. Gerontol. 33 (5), 564-585.

Bennett, M., Ward, E.C., Scarinci, N.A., Waite, M.C., 2015. Service providers' perceptions of working in residential aged care: a qualitative cross-sectional analysis. Ageing Soc 35 (9), 1989-2010.

Bishop, C.E., Weinburg, D.B, Leutz, W, et al., 2008. Nursing assistants' job commitment: effect of nursing home organizational factors and impact on resident well-being. Gerontologist 48 (suppl 1), 36-45.

Bourgeault, I.L., Atanackovic, J., Rashid, A., Parpia, R., 2010. Relations between immigrant care workers and older persons in home and long-term care. Can. J. Aging 29 (1), 109-118.

Bowman, C., Meyer, J., 2017. Care home leadership: action is needed. Age Ageing 46 (4), 534-535.

Broom, M., Marshall, E., 2010. Transformational Leadership in nursing: from Expert Clinician to Influential Leader. Springer, New York, NY.

Brown Wilson, C., 2009. Developing community in care homes through a relationship-centred approach. Health Soc. Care Commun. 17 (2), 177186.

Burns, J., 1978. Leadership. Harper and Row, New York, NY.

Butler, E., Prentiss, A., Benamor, F., 2018. Exploring perceptions of workplace bullying in nursing. Nurs. Health Sci. Res. J. 1 (1), 19-25.

Cammer, A., Morgan, D. Stewart, N., et al., 2014. The hidden complexity of long-term care: how context mediates knowledge translation and use of best practices.(Report)(Author abstract). Gerontologist 54 (6), 1013.

Care Quality Commission, 2019. The State of Health Care and Adult Social Care in England 2018/19. Care Quality Commission, London Editor.

Carpenter, J., Thompson, S., 2008. CNAs' experiences in the nursing home: 'It's in my soul”. J. Gerontol. Nurs. 34 (9), 25.

Carryer, J., Hansen, C.O., Blakey, J.A., 2010. Experiences of nursing in older care facilities in New Zealand. Aust. Health Rev. 34 (1), 11-17.

Casey, D.M.K., Murphy, K., Ni Leime, A., et al., 2011. Dying well: factors that influence the provision of good end-of-life care for older people in acute and long-stay care settings in Ireland. J. Clin. Nurs. 20 (13-14), 1824-1833.

Caspar, S., O'Rourke, N., 2008. The influence of care provider access to structural empowerment on individualized care in long-term-care facilities. J. Gerontol. Ser. B, Psychol. Sci. Soc.Sci. 63 (4), S255-S265.

Castle, N.G., Decker, F.H., 2011. Top management leadership style and quality of care in nursing homes. Gerontologist 51 (5), 630-642.

Chenoweth, L., Forbes, I., Fleming, R., et al., 2014. PerCEN: a cluster randomized controlled trial of person-centered residential care and environment for people with dementia. Int. Psychogeriatr. 26 (7), 1147-1160.

Chenoweth, L., Jeon, Y., Stein-Parbury, J., et al., 2015. PerCEN trial participant perspectives on the implementation and outcomes of person-centered dementia care and environments. Int. Psychogeriatr. 27 (12), 2045-2057.

Cherry, B., Ashcraft, A., Owen, D., 2007. Perceptions of job satisfaction and the regulatory environment among nurse aides and charge nurses in long-term care. Geriatr. Nurs. 28 (3), 183-192. 
Cohen-Mansfield, J., Parpura-Gill, A., 2008. Practice style in the nursing home: dimensions for assessment and quality improvement. Int. J. Geriatr. Psychiatry 23 (4), 376-386.

Colomer, J., de Vries, J., 2016. Person-centred dementia care: a reality check in two nursing homes in Ireland. Dementia 15 (5), 1158-1170.

Cramer, M.E., High, R., Culross, B., et al., 2014. Retooling the RN workforce in long-term care: nursing certification as a pathway to quality improvement. Geriatr. Nurs. 35 (3), 182-187.

Cummings, G.G., MacGregor, T., Davey, M., et al., 2018. Leadership styles and outcome patterns for the nursing workforce and work environment: a systematic review. Int. J. Nurs. Stud. 85, 19-60.

Davidoff, F., Dixon-Woods, M., Leviton, L., Michie, S., 2015. Demystifying theory and its use in improvement. BMJ Qual Saf 24, 228-238.

Dewar, B., Nolan, M., 2013. Caring about caring: developing a model to implement compassionate relationship centred care in an older people care setting. Int. J. Nurs. Stud. 50 (9), 1247-1258.

Dias, N., Mathew, J., Michael, J., 2019. Transformational Leadership in Nursing. Nurse Lead. 17 (5), 432-439.

Donabedian, A., 2005. Evaluating the Quality of Medical Care. Milbank Q. 83 (4), 691-729.

Donaldson, W.V., Vacha-Haase, T., 2016. Exploring staff clinical knowledge and practice with LGBT residents in long-term care: a grounded theory of cultural competency and training needs. Clin. Gerontol. 39 (5), 389-409.

Doody, O., Doody, C., 2012. Transformational leadership in nursing practice. Br. J. Nurs. 21 (20), 1212-1218.

Edvardsson, D., Fetherstonhaugh, D., McAuliffe, L., et al., 2011. Job satisfaction amongst aged care staff: exploring the influence of person-centered care provision. Int. Psychogeriatr. 23 (8), 1205-1212.

Eika, M., et al., 2015a. Nursing staff interactions during the older residents' transition into long-term care facility in a nursing home in rural Norway: an ethnographic study. BMC Health Serv. Res. 15 (1), 125.

Eitienne, E., 2014. Exploring Workplace bullying in nursing. Workplace Health Saf. 62 (1), 6-11.

Eldh, A.C., van der Zijpp, T., McMullan, C., et al., 2016. I have the world's best job' - staff experience of the advantages of caring for older people. Scand. J. Car. Sc. 30 (2), 365-373.

Ericson-Lidman, E., Larsson, L.L.F, Norberg, A., 2014. Caring for people with dementia disease (DD) and working in a private not-for-profit residential care facility for people with DD. Scand. J. Car. Sc. 28 (2), 337-346.

Estabrooks, C.A., Morgan, D.G., Squires, J.E., et al., 2011. The care unit in nursing home research: evidence in support of a definition. BMC Med. Res. Methodol. 11 (1), 46.

Etherton-Beer, C., Venturato, L., Horner, B., 2013. Organisational culture in residential aged care facilities: a cross-sectional observational study. PLoS One 8 (3), e58002 [Electronic Resource].

Fischer, S., 2016. Transformational leadership in nursing: a concept analysis. J. Adv. Nurs. 72 (11), 2644-2653.

Fläckman, B., Hansebo, G., Kihlgren, A., 2009. Struggling to adapt: caring for older persons while under threat of organizational change and termination notice. Nurs. Inq. 16 (1), 82-91.

Forbes-Thompson, S., Leiker, T., Bleich, M.R., 2007. High-performing and low-performing nursing homes: a view from complexity science. Health Care Manag. Rev. 32 (4), 341-351.

Ford, J.A., Wong, G., Jones, A.P., Steel, N., 2016. Access to primary care for socioeconomically disadvantaged older people in rural areas: a realist review. BMJ Open 6 (5), 1-14.

Fossey, J., Garrod, L., Frioland, C.T., et al., 2019. What influences the sustainability of an effective psychosocial intervention for people with dementia living in care homes? A 9 to 12-month follow-up of the perceptions of staff in care homes involved in the WHELD randomised controlled trail. Int. J. Geriatr. Psychiatry 34 (5), 674682.

Gillham, D., De Bellis, A., Xiao, L., et al., 2018. Using research evidence to inform staff learning needs in cross-cultural communication in aged care homes. Nurse Educ. Today 63, 18-23.

Gittell, J.H., Weinburg, D., Pfefferle, S., Bishop, C., 2008. Impact of relational coordination on job satisfaction and quality outcomes: a study of nursing homes. Hum. Resour. Manag. J. 18 (2), 154-170.

Gjerberg, E., Forde, R., Pedersen, R., Bollig, G., 2010. Ethical challenges in the provision of end-of-life care in Norwegian nursing homes. Soc. Sci. Med. 71 (4), 677-684.

Goodman, C., Dening, T., Gordon, A., et al., 2016. Effective health care for older people living and dying in care homes: a realist review. BMC Health Serv. Res. 16 (1).

Grimshaw, J., Ivers, N., Linklater, S., et al., 2019. Reinvigorating Stagnant science: Implementation laboratories and a Meta-Laboratory to Efficiently Advance the Science of Audit and Feedback, 28. BMJ Quality and Safety, pp. 416-423.

Hafford-Letchfield, T., Simpson, P., Willis, P.B., Almack, K., 2018. Developing inclusive residential care for older lesbian, gay, bisexual and trans (LGBT) people: an evaluation of the Care Home Challenge action research project. Health Soc. Care Commun. 26 (2), e312-e320.

Han, K., Trinkkoff, A.M., Storr, C., et al., 2014. Associations between state regulations, training length, perceived quality and job satisfaction among certified nursing assistants: cross-sectional secondary data analysis. Int. J. Nurs. Stud. 51 (8), 1135-1141
Havig, A.K., Skogstad, A., Kjekshus, L.E., Romoren, T.I, 2011. Leadership, staffing and quality of care in nursing homes. BMC Health Serv. Res. 11 (1), 327.

Hoffmann, TC. Glasziou, P.P. Boutron, I. et al. 2014. Better reporting of interventions: template for intervention description and replication (TIDieR) checklist and guide. BMJ: Br. Med. J. 348 (mar07 3), g1687.

Hunt, S.R., Corazzini, K., Anderson, R.A., 2014. Top nurse-management staffing collapse and care quality in nursing homes. J. Appl. Gerontol. 33 (1), 51-74.

Irving, J., 2015. Beyond family satisfaction: family-perceived involvement in residential care: family involvement in residential care. Australas. J. Ag. 34 (3), 166-170.

Ivers, N.M., Desveaux, L., Presseau, J., et al., 2017. Testing feedback message framing and comparators to address prescribing of high-risk medications in nursing homes: protocol for a pragmatic, factorial, cluster-randomized trial. Implement. Sci.: IS 12 (1), 86.

Jack, K., Tetley, J., Chambers, A., 2019. The education of nurses working in care homes for older people: an appreciative inquiry. J. Older People Nurs. $14(2)$ p. n/a-n/a.

Jacobsen, F.F., Day, S., Laxer, K., et al., 2018. Job autonomy of long-term residential care assistive personnel: a six country comparison. Ageing Int. 43 (1), 4-19.

Jones, C., Moyle, W., 2016. Staff perspectives of relationships in aged care: a qualitative approach. Australas. J. Ageing 35 (3), 198-203.

Karsh, B., Booske, B.C., Sainfort, F., 2005. Job and organizational determinants of nursing home employee commitment, job satisfaction and intent to turnover. Ergonomics 48 (10), 1260-1281.

Kirkup, B., 2015. The Report of the Morecambe Bay Investigation. The Stationary Office, London.

Kitwood, T.M., 1997. Dementia reconsidered: the Person Comes first. Rethinking ageing Series. Open University Press, Buckingham.

Kjøs, В.Ø., Botton, G., Gjevjon, E.R., Romoren, T.I, 2010. Quality work in long-term care: the role of first-line leaders. Int. J. Qual. Health Care: J. Int. Soc. Qual. Health Care 22 (5), 351-357.

Knopp-Sihota, J.A., Niehaus, L., Squires, J.E., et al., 2015. Factors associated with rushed and missed resident care in western Canadian nursing homes: a crosssectional survey of health care aides. J. Clin. Nurs. 24 (19-20), 2815-2825.

Kontos, P.C., Miller, K.-.L., Mitchell, G.J., 2010. Neglecting the importance of the decision making and care regimes of personal support workers: a critique of standardization of care planning through the RAI/MDS. Gerontologist 50 (3), 352-362.

Kuo, H.T., Yin, T.J.C., Li, I.C., 2008. Relationship between organizational empowerment and job satisfaction perceived by nursing assistants at long-term care facilities. J. Clin. Nurs. 17 (22), 3059-3066.

Kusmaul, N., Bunting, M., 2017. Perspectives on caregiving: a qualitative evaluation of certified nursing assistants. Geriatr. Nurs. 38 (2), 146-151.

Laing, W., 2008. Calculating a Fair Price For Care A toolkit For Residential and Nursing Care Costs. Laing \& Buisson, London.

Lea, E.J., Goldberg, L.R., Price, A.D., et al., 2017. Staff awareness of food and fluid care needs for older people with dementia in residential care: a qualitative study. J. Clin. Nurs. 26 (23-24), 5169-5178.

Leedahl, S.N., Chapin, R.K., Little, T.D., 2015. Multilevel examination of facility characteristics, social integration, and health for older adults living in nursing homes. J. Gerontol. B Psychol. Sci. Soc. Sci. 70 (1), 111-122.

Lynch, B., McCance, T., McCormack, B., Brown, D., 2018. The development of the Person Centred situational leadership framework: revealing the being of person centredness in nursing homes. J. Clin. Nurs. 27 (1-2), 427-440.

Lyons, S.S., 2010. How do people make continence care happen? An analysis of organizational culture in two nursing homes. Gerontologist 50 (3), 327-339.

Madden, C., Clayton, M., Canary, H., et al., 2017. Rules of performance in the nursing home: a grounded theory of nurse-CNA communication. Geriatr. Nurs. 38 (5), 378-384.

Mallidou, A.A., Cummings, G.G., Schlam, C., Estabrooks, C., 2013. Health care aides use of time in a residential long-term care unit: a time and motion study. Int. J. Nurs. Stud. 50 (9), 1229-1239.

McCormack, B., McCance, T.V., 2006. Development of a framework for person-centred nursing. J. Adv. Nurs. 56 (5), 472-479.

McCormack, B., McCance, T.V., 2010. Person-Centred Nursing: Theory and Practice. John Wiley \& Sons, Hoboken Incorporated.

McCormack, B., Roberts, T., Meyer, J., et al., 2012. Appreciating the 'person' in long-term care. J. Older People Nurs. 7 (4), 284-294.

McGilton, K.S., Boscart, V.M, Brown, M., Bowers, B., 2014. Making tradeoffs between the reasons to leave and reasons to stay employed in long-term care homes: perspectives of licensed nursing staff. Int. J. Nurs. Stud. 51 (6), 917-926.

Michie, S., van Stralen, M.M., West, R., 2011. The behaviour change wheel: a new method for characterising and designing behaviour change interventions. Implementat. Sci. 6 (1), 42.

Nakrem, S., 2015. Understanding organizational and cultural premises for quality of care in nursing homes: an ethnographic study. BMC Health Serv. Res. 15, 508.

NHS England, Winterbourne View - time for Change. 2014: NHS England London.

Nolan, M.R., Davies, S., Brown, J., Nolan, J., 2004. Beyond 'person-centred' care: a new vision for gerontological nursing. J. Clin. Nurs. 13, 45-53.

Nolan, M., Davies, S., Brown, J., 2006. Transitions in care homes: towards relationship-centred care using the 'Senses Framework'. Qual. Ageing Older Adults 7 (3), $5-14$.

Orellana, K., Manthorpe, J., Moriarty, J., 2017. What do we know about care home managers? Findings of a scoping review. Health Soc. Care Commun. 25 (2), 366-377. 
Pawson, R., Tilley, N., 1997. Realistic Evaluation. Sage, London.

Pawson, R., Greenhalgh, T., Harvey, G., Walshe, K., 2004. Realist synthesis: an introduction. ESRC Research Methods Programme. University of Manchester, Manchester.

Owen, T., Meyer, J., Cornell, P., et al., Joseph Rowntree Foundation, 2015. My Home Life: Promoting Quality of Life in Care Homes. J.R. Foundation, London Editor.

Pawson, R., et al., 2005. Realist review-a new method of systematic review designed for complex policy interventions. J. Health Serv. Res. Policy (10 Suppl 1) 21-34.

Pearson, M., Brand, S.L., Quinn, C., et al., 2015. Using realist review to inform intervention development: methodological illustration and conceptual platform for collaborative care in offender mental health. Implement. Sci.: IS 10 (1), 134.

Penney, S., Ryan, A., 2018. The effect of a leadership support programme on care home managers. Nurs. Older People 30 (1), 35-40.

Powell, C., Blighe, A., Frogatt, K., et al., 2018. Family involvement in timely detection of changes in health of nursing homes residents: a qualitative exploratory study. J. Clin. Nurs. 27 (1-2), 317-327.

Puurveen, G., Baumbusch, J., Gandhi, P., 2018. From family involvement to family inclusion in nursing home settings: a critical interpretive synthesis. J. Fam. Nurs. 24 (1), 60-85.

Rantz, M.J., Hicks, L., Grando, V., et al., 2004. Nursing home quality, cost, staffing, and staff mix. Gerontologist 44 (1), 24-38.

Rapaport, P., Livingston, G., Murray, J., et al., 2017. Systematic review of the effective components of psychosocial interventions delivered by care home staff to people with dementia. BMJ Open 7 (2), e014177.

Rittel, H., Webber, M., 1973. Dilemmas in a general theory of planning. Policy Sci. 4 (2), 155-169.

Rokstad, A.M.M., Vatne, S., Engedal, K., Selbaek, G., 2015. The role of leadership in the implementation of person-centred care using Dementia Care Mapping: a study in three nursing homes. J. Nurs. Manag. 23 (1), 15-26.

Rondeau, K.V., Wagar, T.H., 2006. Nurse and resident satisfaction in magnet long-term care organizations: do high involvement approaches matter? J. Nurs. Manag. 14 (3), 244-250.

Scalzi, C.C., Evans, L.K., Barstow, A., Hostvedt, K., 2006. Barriers and enablers to changing organizational culture in nursing homes. Nurs. Adm. Q. 30 (4), 368-372.

Schneider, W., 1994. The Reengineering alternative: a Plan For Making Your Current Culture Work ed. N. York. Irwin, NY.

Scott-Cawiezell, J., Main, D.S, Vojir, C.P, et al., 2005. Linking nursing home working conditions to organizational performance. Health Care Manage. Rev. 30 (4), 372-380.

Skills for Care, The State of the Adult Social Care Sector and Workforce in England. 2018: London.

Sion, K., Verbeek, H., de Boer, B., et al., 2020. How to assess experienced quality of care in nursing homes from the client's perspective: results of a qualitative study. BMC Geriatr. 20 (1), 1-12.

Skovdahl, K., Kihlgren, A.L., Kihlgren, M., 2003. Different attitudes when handling aggressive behaviour in dementia-narratives from two caregiver groups. Aging Ment. Health 7 (4), 277-286.

Social Care Institute for Excellence, 2017. Person Centred Care For Older People in Care Homes. SCIE, London Editor.

Soklaridis, S., Ravitz, P., Adler Nevo, G., Lieff, S., 2016. Relationship-centred care in health: a 20-year scoping review. Patient Exp. J. 3 (1), 130-145.
Spilsbury, K, Hewitt, C., Stirk, L., Bowman, C., 2011. The relationship between nurse staffing and quality of care in nursing homes: a systematic review. Int. J. Nurs. Stud. 48 (6), 732-750.

Spilsbury, K., Thompson, C., Alldred, D., et al., 2017. Relationship Between Care Home Staffing and Quality of care: a Mixed Methods Approach. National Institute of Health Research, Leeds.

Strandmark, M., Rahm, G., Rystedt, I., et al., 2019. Managing bullying in Swedish workplace settings: a concealed and only partially acknowledged problem. J. Nurs. Manag. 27 (2), 339-346.

Swagerty, D.L., Lee, R., Smith, B., Taunton, R.L., 2005. The context for nursing home resident care: the role of leaders in developing strategies. J. Gerontol. Nurs. 31 (2), 40-48.

The Mid Staffordshire NHS Foundation Trust, Report of the Mid Staffordshire NHS Foundation Trust Public Inquiry. 2013: London.

The National Skills Academy for Social Care, A.S.F.C., The Leadership Qualities Framework. 2014: Leeds.

Tjia, J., Lemay, C.A, Bonner, A., et al., 2017. Informed family member involvement to improve the quality of dementia care in nursing homes. J Am Geriatr Soc 65 (1), 59-65.

Tong, M., Schwendimann, R., Zúñiga, F., 2017. Mobbing among care workers in nursing homes: a cross-sectional secondary analysis of the Swiss Nursing Homes Human Resources Project. Int. J. Nurs. Stud. 66, 72-81.

Tresolini, C.P., Pew-Fetzer Task Force, 1994. Health Professions Education and Relationship-centered Care. Pew Health Professions Commission, San Francisco.

Trinkoff, A.M., Storr, C.L., Lerner, N.B., et al., 2017. CNA training requirements and resident care outcomes in nursing homes. Gerontologist 57 (3), 501-508.

Vandrevala, T., Samsi, K., Rose, S., et al., 2017. Perceived needs for support among care home staff providing end of life care for people with dementia: a qualitative study. Int. J. Geriatr. Psychiatry 32 (2), 155-163.

Vassba, T.K., Kirkevold, M., Edvardsson, D., et al., 2019. The meaning of working in a person-centred way in nursing homes: a phenomenological-hermeneutical study. BMC Nurs. 18 (1).

Verbeek, H.Z., van Rossum, E., Zwakhalen, S.M.G., et al., 2009. Small, homelike care environments for older people with dementia: a literature review. Int. Psychogeriatr. 21 (2), 252-264.

Vermeerbergen, L., Van Hootegem, G., Benders, J., 2017. A comparison of working in small-scale and large-scale nursing homes: a systematic review of quantitative and qualitative evidence. Int. J. Nurs. Stud. 67, 59-70.

Watson, J., 2019. Developing the Senses Framework to support relationship-centred care for people with advanced dementia until the end of life in care homes. Dementia 18 (2), 545-566.

Wong, G., Pawson, R., Owen, L., 2011. Policy guidance on threats to legislative interventions in public health: a realist synthesis. BMC Public Health 11 (1), 222.

Wong, G., Westhorp, G., Manzano, A., et al., 2016. RAMESES II reporting standards for realist evaluations. BMC Med. 14 (1), 96.

Yeatts, D.E., Cready, C.M., 2007. Consequences of empowered CNA teams in nursing home settings: a longitudinal assessment.(certified nurse aides). Gerontologist 47 (3), 323-339.

Zeller, A., Muller, M., Needham, I., et al., 2014. Dealing with aggressive behaviour in nursing homes: caregivers' use of recommended measures. J. Clin. Nurs. 23 (17-18), 2542-2553. 